\title{
How Educator's Self-Efficacy affects Integration of Technology in the Classroom Teaching: Excerpts from +2 Schools of Meghalaya
}

\author{
Blizzard R. Marak \\ Research Scholar, Department of Management, North-Eastern Hill University, Tura Campus, Meghalaya
}

\begin{abstract}
This paper is an evaluative study to understand how self efficacy of the educators plays a role in integration of technology in the classroom teaching. For this, the +2 schools of Meghalaya belonging to different streams - Arts, Science and Commerce were taken up. A total of 500 numbers of +2 educators in the state of Meghalaya were randomly picked up for participation and out that 417 respondents were selected for analysis fulfilling criteria for enumeration. The educators who participated in the research were divided into three zones according to the types of school they are employed. Zone was divided into three sections- Garo Hills, Khasi Hills and Jaintia Hills and selected types of schools were- Govt., Deficit, Adhoc and Private schools. Educators from all categories were selected randomly and the criteria for selection were that minimum existential operation of a particular school should not be less than 5 years. Semi-structured questionnaire was provided to the educators in order to understand how much self efficacy influenced integration of technology in classroom teaching. The research tested three hypotheses. The findings revealed that there is a significant impact of self efficacy in the integration of technology in the classroom teaching of +2 Schools of Meghalaya.
\end{abstract}

Keywords: self-efficacy, educators, classroom teaching, technology, meghalaya,

\section{INTRODUCTION}

The word "technology integration" may be perhaps be considered as one of the most burning topic of the hour in today's world which reflects a numerous meaning and can be inscribed into uncountable meaning. Though most of the people know its importance and how it is important to the students, likewise people know how to integrate it the present system of classroom teaching in today's education system but lot of arguments and obstacles are always cropping up from time to time when it comes to real implementation stage.

Technology integration in the classroom has become an important aspect of successful teaching. It has triggered many researchers to investigate different aspects of such integration (e.g., Kotrlik \& Redmann, 2005; Bauer \& Kenton, 2005; Judson, 2006; Totter et al., 2006; ChanLin et al., 2006; Zhao, 2007; Gulbahar, 2007; Anderson \& Maninger, 2007; Abbit \& Klett, 2007; and Wood \& Ashfield, 2008). This is because it allows students to learn more in less time and allows schools to focus on global learning environments if used appropriately. In addition, it could be an effective teaching tool when used to engage all students in the learning.

In recent years, the integration of technology into classroom teaching has been a major focus of state run schools, deficit and private educational organizations. It has become the responsibility of teacher preparation programs at institutions of higher education to prepare teachers that are capable of using technology in effective and efficient ways to positively influence student achievement. However, there is notable no record of the courses designed to prepare educators of +2 schools of Meghalaya state to effectively use technology in the practice of teaching. Even though some of these educators focus on developing the technical skills of by themselves needed to use specific technologies that they might encounter to integrate technology in their classroom teaching while others focus on traditional concepts of teaching with without technology. Bandura (1997) describes perceived self-efficacy as "beliefs in one's capabilities to organise and execute the courses of action required to produce given attainments." As this applies to the integration of technology into education, self-efficacy beliefs toward technology integration have been theorized to be a determining factor in how well a teacher is able to effectively use technology to improve teaching and learning (Albion, 2001; Enochs, Riggs, \& Ellis, 1993; Kellenberger, 1996; Riggs \& Enochs, 1993; Wang, Ertmer, \& Newby, 2004a). Simply stated, a teacher's perception that he or she can effectively use technology in the process of teaching and learning will impact that teacher's ability to do so. However, the factors that influence self-efficacy beliefs towards technology integration remain largely ambiguous, particularly when examining the possible influences of students' attitudes towards technology and also the influences of their coursework as a teacher for the +2 students.

The purpose of the pilot research study is to examine the relationship between self efficacy beliefs towards the integration of technology into classroom teaching of educators of +2 schools. Recent research in this area has focused primarily on the relationship among attitudes toward computer technology and perceived 
self-efficacy relating only to computer usage behaviour (Compeau \& Higgins, 1995; Karsten \& Roth, 1998; Torkzadeh, Koufteros, \& Pflughoeft, 2003; Zhang \& Espinoza, 1998). However, this recent research has not specifically investigated the possible relationship among these measures and the perceived ability to effectively integrate technology into +2 schools' classroom teaching practices. This pilot study will expand on this recent research to investigate this relationship between the self efficacy attitudes toward computer technology of educators of +2 schools into the practice of teaching. Of particular interest to this study is the impact of the four types of schools offering +2 courses in different streams to effective integrate technology into teaching practices. Additionally, this pilot study provides insight into the use of distinct survey in better understanding the relationship of between self efficacy and types of school in Meghalaya to integrate technology into class room teaching.

\section{Research Questions}

This exploratory study focused on two primary research questions:

1. Whether there are any significant changes in self-efficacy beliefs toward technology integration within any of the three courses?

2. Whether the usefulness of technology depends on the stream they are teaching?

\section{Research hypotheses}

There are three main hypotheses in the present study, which are listed as follows:

H1: The more positive attitude towards technology will base on the stream and type of school they are teaching. $\mathrm{H} 2$ : The more positive attitude towards usefulness of technology will base on the stream and type of school.

H3: The usefulness of technology is reduced because of stream and type of school.

\section{REVIEW OF LITERATURE}

The concept of self-efficacy development is most commonly associated with the work of American psychologist Albert Bandura who stated "one's belief is in one's ability to succeed in specific situations or accomplish a task". The literature review was undertaken to explore the ways in which researchers and practitioners have employed the concept of self-efficacy to integrate the technology in the classroom teaching for the daily classes the educators are involved in. The review was concerned with integration of technology in +2 schools for the classroom teaching which will result in a great impact on the use of technology in the education system. Even though there has been a notable amount of research conducted which examined the attitudes of teachers towards computer technology (Milbrath \& Kinzie, 2000; Torkzadeh \& Koufteros, 1994; Karsten \& Roth, 1998; Kinzie, Delcourt, \& Powers, 1994; Torkzadeh \& Van Dyke, 2002), these researches has focused primarily on attitudes influencing basic usage of computer technology and has not examined teachers' attitudes toward using technology in the practice of teaching. Other studies have examined on the development of technical skills as a result of professional preparation or professional development programs (Albion, 2001; Kellenberger, 1996; Mourson \& Bielefeldt, 1999; Wang et al., 2004a). However, few studies have been conducted that investigate the nature of self-efficacy in teaching with technology (Albion, 2001; Enochs et al., 1993; Riggs \& Enochs, 1993; Wang, Ertmer, \& Newby, 2004b) and little research that has attempted to identify the relationship between attitudes towards computer technology, types of schools, and the subjects they teach to effectively integrate technology into their teaching practice.

Among the earliest researches on self-efficacy beliefs toward the use of technology in teaching and learning was conducted by Enoch et al. (1993). This study focused on the development and validation of a survey instrument that would provide insight into the self-efficacy beliefs of in-service teachers toward the use of computer technology in classroom teaching practices. The Microcomputer Utilization in Teaching Efficacy Beliefs Instrument (MUTEBI) developed by the Enochs et al. (1993) included subscale measurements for Personal Self-Efficacy (SE) and Outcome Expectancy (OE). Personal Self Efficacy was defined as "teachers' beliefs in their own ability to utilize the microcomputer for effective instruction." Outcome Expectancy was described as teachers' beliefs regarding their responsibility for students' ability or inability to use computer technology in the classroom. While this study was able to establish the validity and reliability of the MUTEBI instrument and the distinct nature of the two subscale measures, there has been little published research beyond this. To further investigate relationship of these measures to other factors that either influence or are influenced by self-efficacy beliefs toward the use of technology in classroom teaching, further studies deemed important. Further, the relevance of this research to the current state of technology use in teaching and learning is limited by the significant changes in the technology available in +2 school classrooms of Meghalaya. It is for this reason that new research is necessary to advance the understanding of self-efficacy beliefs toward technology integration.

Since the Enochs et al study in 1993, more recent research has been conducted examining beliefs toward technology. However, much of this research has focused on factors that influence attitudes toward 
computer technology (Kellenberger, 1996; Torkzadeh \& Koufteros, 1994; Torkzadeh et al., 2003; Torkzadeh \& van Dyke, 2001). The research regarding beliefs toward technology has focused on a broader uses of technology and not on the integration of technology into teaching. These studies have, however, provided insight into the relationship between self-efficacy beliefs toward technology in predicting usage behavior and also in developing instrumentation that is capable of reliably measuring attitudes toward technology.

In a recent study conducted by Wang et al. (2004a), goal setting activities and vicarious learning experiences in which pre-service teachers reviewed video segments and other artifacts from K-12 classrooms were determined to have a significant influence on self-efficacy beliefs toward technology integration.

Researchers and staff developers have suggested numerous and disparate factors that may influence the degree to which educators implement and persist in the implementation of educational innovations in general. These include personal and demographic factors related to educators, the quality of professional development offered to teachers, the extent to which administrative and curricular support is available to teachers, as well as the quality of teacher access to computer resources. Several studies have reported relationships between demographic characteristics of teachers and their reported use of technologies; age, gender, race, education level, socio-economic status of students taught, years of teaching, years of technology use, specializations, and size of school were among the factors reported in key literature (Becker, 1994; Ely, 1999; Hadley \& Sheingold, 1993; Jaber \& Moore, 1999).

Based on the above mentioned studies, effort has been made to examine the role of self efficacy in technology integration by the educators of the +2 schools of Meghalaya. Factors considering the type of school educators are employed in and the streams where they are teaching have been taken into consideration for measuring the role of self-efficacy towards the integration of technology in the classroom teaching.

\section{Research Questions investigated}

Specifically the study sought answer to the following questions:

i. Whether there is any impact of comfort/anxiety of educators on use of technology in stream and types of school.

ii. Whether the usefulness of technology depends on the stream and type of school.

iii. Whether there is any negative impact of usefulness of technology related with the stream and type of school they teach.

\section{Purpose of the Study}

Meghalaya compared to other states of the country is very small with a small number of populations but education is delivered to students at par with the rest of the state. Meghalaya government has categorized schools into three types. +2 schools impart education in three streams i.e. Arts, Science and Commerce. Though government has got the record of number of schools existing in Meghalaya state but no study has been conducted so far according to researcher's knowledge about the role of se-efficacy towards the usage of technology in classroom teaching of that school. In view of the above, this study seeks to look into how educators' self efficacy plays a role in the integration of technology in their classroom teaching, whether influence of technology is limited to streams or types of school they are employed. Therefore, the study was designed in the first place to measure and analyse self efficacy of educators towards technology usage in their class room teaching in +2 schools of Meghalaya. It will also explore possible relations between streams or subjects the educators teach in their schools.

\section{Sample and Sampling Procedure}

\section{METHOD}

In Meghalaya, there are 345 schools offering +2 courses in the disciplines of Arts, Science or Commerce subject. For this study, the schools located in different areas were divided into three major zones Garo Hills, Khasi Hills and Jaintia Hills zones. The stratified proportional random sampling procedure was used to select 6 educators from each of the 345 schools. The simple random sampling procedure was then used to select schools located in three different zones. A total of 500 teachers participated in the study. However, out of these 500 teachers, only 417 completed usable questionnaires were found for final analysis. Prior to the data collection from different schools, permission was taken from the school authority to involve the educators of the +2 schools.

\section{Research Instruments}

Data for the study were collected using the instrument of semi structured questionnaire. The questionnaire was framed to collect the information of the educators' self efficacy role in usage of technology in their classroom teaching. In order to derive the information about the role of self-efficacy towards the use of technology, questionnaire was divided into three divisions. The first part of the questionnaire was designed to 
collect information about comfort/anxiety of the educators in using the present technology in their classroom teaching. The second part was all about the usefulness of the technology according to educators and the third section was negatively phrased about the usage of technology in order to explore the effectiveness of the technology against the traditional teaching strategies in the classroom. An effort has been made to understand the role of self efficacy through the questionnaire framed for the educators belonging to different streams-Arts, Science and Commerce.

\section{Data Collection Instrument}

Apart from sending the questionnaires by post and email, all the +2 schools educator respondents were approached by the researcher personally with prior permission from the Head of the Institution. The questionnaire was asked to be filled in complete anonymity so as to avoid teachers presenting artificial behaviours that they would not have displayed in normal situations. The teachers were given a maximum of 30 minutes to fill out the questionnaire. They were assured that the completed questionnaires were confidential. The questionnaires were completed and collected on the spot. The questionnaire was collected on the site in order to give the educators a chance to consider their responses in the present situation in which they are working.

\section{Analysis}

All the three hypotheses were tested by applying Single factor ANOVA. The null hypotheses were rejected or not rejected, depending on whether the calculated $\mathrm{F}$ ratio was significant of the probability level of 0.05 (or $5 \%$ ).

\section{RESULTS AND DISCUSSION}

H1: There is no significant difference among educators in their comfort/anxiety towards technology usage depending on the stream and type of school in their classroom teaching in the +2 schools of Meghalaya

\section{Descriptive}

Table 1.1 - Stream -Arts, Science and Commerce

\begin{tabular}{|l|l|r|r|r|}
\hline Schol_category & STREAM & Mean & Std. Deviation & N \\
\hline Govt. & Arts & 5.12 & 1.518 & 73 \\
& Science & 5.00 & 1.673 & 36 \\
& Commerce & 6.21 & 1.357 & 19 \\
& Total & 5.25 & 1.582 & 128 \\
Deficit & Arts & 5.25 & 1.640 & 53 \\
& Science & 5.63 & 1.527 & 24 \\
& Commerce & 5.57 & .852 & 14 \\
& Total & 5.40 & 1.512 & 91 \\
Adhoc & Arts & 5.40 & 1.476 & 62 \\
& Science & 5.21 & 1.893 & 28 \\
& Commerce & 6.05 & 1.169 & 39 \\
& Total & 5.56 & 1.520 & 129 \\
Private & Arts & 5.36 & 1.303 & 42 \\
& Science & 5.89 & .928 & 9 \\
& Commerce & 4.89 & 1.875 & 18 \\
& Total & 5.30 & 1.448 & 69 \\
& Arts & 5.27 & 1.494 & 230 \\
& Science & 5.30 & 1.659 & 97 \\
& Commerce & 5.78 & 1.404 & 90 \\
& Total & 5.39 & 1.526 & 417 \\
\hline
\end{tabular}


How Educator's Self-Efficacy affects Integration of Technology in the Classroom Teaching: ..

\section{ANOVA}

Table1.2- Stream -Type of school

\begin{tabular}{|l|r|r|r|r|r|}
\hline Source & \multicolumn{1}{|c|}{ Type III Sum of } & & & & \multicolumn{1}{c|}{ Squares } \\
Corrected Model & $51.086(\mathrm{a})$ & 11 & 4.644 & 2.049 & .023 \\
Intercept & 8705.184 & 1 & 8705.184 & 3841.553 & .000 \\
School_category & $\mathbf{1 . 2 8 3}$ & $\mathbf{3}$ & $\mathbf{. 4 2 8}$ & $\mathbf{. 1 8 9}$ & $\mathbf{. 0 4}$ \\
STREAM & $\mathbf{9 . 2 6 3}$ & $\mathbf{2}$ & $\mathbf{4 . 6 3 1}$ & $\mathbf{2 . 0 4 4}$ & $\mathbf{. 1 3 1}$ \\
School_category * & $\mathbf{2 9 . 0 1 4}$ & $\mathbf{6}$ & $\mathbf{4 . 8 3 6}$ & $\mathbf{2 . 1 3 4}$ & $\mathbf{. 0 4 9}$ \\
STREAM & 917.754 & 405 & 2.266 & & \\
Error & 13066.000 & 417 & & & \\
Total & 968.839 & 416 & & & \\
Corrected Total & & & & & \\
\hline
\end{tabular}

\section{Analysis for $\mathrm{H1}$}

From the descriptive Table 1.1 we find that the average level of comfort/anxiety on use of technology 5.39 derived from all the respondents taken together collective from different streams and types of school. This indicates that all the respondents are in more or less comfortable in using the current technology in their daily life which will be affected in their classroom teaching. The average level of comfort/anxiety by the use of technology in commerce stream is found to be the highest with average mean value of 7.78 (on 2 point rating scale). Followed by the educators belong to Science stream with the average mean value of 5.30 (on 2 point rating scale). The educators belonging to Arts stream have the lowest average mean with the mean value of 5.27 (on 2 point rating scale). The reading from the table 4.3 clearly depicted that educators belonging to Commerce streams are more comfortable in using current technology available for the daily life as well for the classroom teachings in +2 schools of Meghalaya.

Conclusion from table 4.5 can also be drawn can be drawn for the responses from different types of school comfort/anxiety on current use of technology. Table clearly shows that average mean for Adhoc school has got the highest with the mean value of 5.56(on 2 scale rating). Followed by the deficit school with the average mean value of 5.40( 2 scale rating). The value of mean for Private school is the second lowest with the mean value of 5.30 ( in 2 scale rating). Surprisingly, average mean of the Govt. school is the lowest with the mean value of 5.27(on 2 scale rating). This clearly indicates that educators from Adhoc schools are more comfortable in using current technology compared to other educators belonging to different schools.

From the ANOVA Table 1.2 the F value for types of school is 4.303 and degree of freedom 3 with the corresponding p- value 0.404 which is greater than the level of significance 0.05 .

Similarly from ANOVA table 1.2 the value of $\mathrm{F}$ for the stream is 10.323 and degree of freedom is 2 with the corresponding $\mathrm{p}$ - value of 0.0000 which is smaller than the level of significant.

ANOVA table 1.2 clearly indicates that the value of $\mathrm{F}$ for Type of School * stream is 3.686 and degree of freedom is 6 with the corresponding p-value 0.001 which is smaller than the level of significant. Hence we can reject the null hypothesis $\mathbf{H O}_{2}$.

\section{Findings:}

On the basis of analysis conducted for $\mathbf{H O}_{\mathbf{1}}$ after testing through Two Factor ANOVA, it is found that there is a comfort/anxiety for use of technology is affected by the type of school they are employed but the use of technology does not affected by the stream. Hence our result from ANOVA test indicates that educators are comfort/anxiety to use technology is not affected even if they are working in different type of schools teaching in different streams.

$\mathrm{HO}_{2}$ : There is no significant difference in the usefulness of technology by the educators' on the basis of different streams or subjects being imparted in the classroom Descriptive 
Table 2.1 - Stream -Type of School

\begin{tabular}{|l|l|l|l|l|}
\hline Schol_category & STREAM & Mean & Std. Deviation & N \\
\hline Govt. & Arts & 4.01 & 1.399 & 73 \\
& Science & 2.86 & 1.775 & 36 \\
& Commerce & 4.47 & .612 & 19 \\
& Total & 3.76 & 1.541 & 128 \\
& Arts & 4.42 & .929 & 53 \\
& Science & 4.42 & 1.060 & 24 \\
Adhoc & Commerce & 4.57 & .756 & 14 \\
& Total & 4.44 & .933 & 91 \\
& Arts & 4.08 & 1.045 & 62 \\
& Science & 3.71 & 1.697 & 28 \\
Private & Commerce & 4.33 & 1.132 & 39 \\
& Total & 4.08 & 1.248 & 129 \\
& Arts & 4.26 & 1.083 & 42 \\
& Science & 2.11 & 1.764 & 9 \\
Total & Commerce & 3.89 & .832 & 18 \\
& Total & 3.88 & 1.323 & 69 \\
& Arts & 4.17 & 1.157 & 230 \\
& Science & 3.42 & 1.743 & 97 \\
& Commerce & 4.31 & .944 & 90 \\
& Total & 4.03 & 1.320 & 417 \\
\hline
\end{tabular}

\section{ANOVA}

Table2.2- Stream -Type of school

\begin{tabular}{|l|r|r|r|r|r|}
\hline Source & $\begin{array}{c}\text { Type III Sum } \\
\text { of Squares }\end{array}$ & df & Mean Square & \multicolumn{1}{c|}{ F } & \multicolumn{1}{c|}{ Sig. } \\
\hline Corrected Model & $110.788(\mathrm{a})$ & 11 & 10.072 & 6.644 & .000 \\
Intercept & 4498.404 & 1 & 4498.404 & 2967.566 & .000 \\
Schol_category & 35.114 & 3 & 11.705 & 7.722 & .000 \\
STREAM & 54.331 & 2 & 27.165 & 17.921 & .000 \\
Schol_category* & 35.417 & 6 & 5.903 & 3.894 & .001 \\
STREAM & 613.922 & 405 & 1.516 & & \\
Error & 7485.000 & 417 & & & \\
Total & 724.710 & 416 & & & \\
Corrected Total & & & & & \\
\hline
\end{tabular}

\section{Analysis for $\mathrm{H}_{2}$}

From the descriptive Table 2.1 we find that the average level of usefulness of technology 4.03 is derived from all the respondents taken together collective from different streams and types of school. This indicates that all the respondents are in more or less find the technology useful in their daily life which will be effected in their classroom teaching. The average level of usefulness of technology in the classroom teaching in commerce stream is found to be the highest with average mean value of 4.31 (on 2 point rating scale). Followed by the educators belong to Arts stream with the average mean value of 4.17 (on 2 point rating scale). The educators belonging to Science stream have the lowest average mean with the mean value of 3.42 (on 2 point rating scale). The reading from the table 2.1 clearly depicted that educators belonging to Commerce streams are find the use of technology more effective for the daily life as well for the classroom teachings in +2 schools of Meghalaya.

Conclusion from table 2.1 can also be drawn can be drawn for the responses from different types of school for usefulness of current technology. Table clearly shows that average mean for Deficit school has got the highest with the mean value of 4.44(on 2 scale rating). Followed by the Adhoc school with the average mean value of 4.08(2 scale rating). The value of mean for Private school is the second lowest with the mean value of 
3.88( in 2 scale rating). Surprisingly, in this section of examination, average mean of the Govt. school is the lowest with the mean value of 3.76(on 2 scale rating). This clearly indicates that educators from Deficit schools are find technology usage more useful in the classroom teaching compared to other educators belonging to different schools.

From the ANOVA Table 2.2 the F value for types of school is 4.303 and degree of freedom 3 with the corresponding p- value 0.404 which is greater than the level of significance 0.05 .

Similarly from ANOVA table 2.2 the value of $F$ for the stream is 10.323 and degree of freedom is 2 with the corresponding p- value of 0.0000 which is smaller than the level of significant. Hence

ANOVA table 4.8 clearly indicates that the value of $\mathrm{F}$ for Type of School * stream is 3.686 and degree of freedom is 6 with the corresponding p-value 0.001 which is smaller than the level of significant. Hence we can reject the null hypothesis $\mathbf{H O}_{2}$.

Findings:

On the basis of analysis conducted for $\mathbf{H 0}_{2}$ after testing through Two Factor ANOVA, it is found that there is a usefulness of technology is affected by the type of school they are employed but the effective usefulness of technology does not affected by the stream. Hence our result from ANOVA test indicates that usefulness of technology is not affected even if they are teaching in different subjects in different schools.

$\mathrm{HO}_{3}$ : There is no significant difference in the not usefulness of technology on the basis of stream educators teach and the types of school educators are teaching

\section{Descriptive}

Table 3.1 - Stream -Arts, Science and Commerce

\begin{tabular}{|l|l|r|r|r|}
\hline Schol_category & STREAM & Mean & Std. Deviation & N \\
\hline Govt. & Arts & 4.62 & 1.542 & 73 \\
& Science & 5.17 & 1.231 & 36 \\
& Commerce & 5.79 & .918 & 19 \\
& Total & 4.95 & 1.438 & 128 \\
Deficit & Arts & 3.72 & 1.994 & 53 \\
& Science & 4.25 & 1.984 & 24 \\
& Commerce & 3.79 & 2.778 & 14 \\
& Total & 3.87 & 2.115 & 91 \\
Adhoc & Arts & 4.34 & 1.619 & 62 \\
& Science & 5.11 & 1.257 & 28 \\
& Commerce & 4.31 & 2.054 & 39 \\
& Total & 4.50 & 1.714 & 129 \\
& Arts & 4.48 & 1.418 & 42 \\
& Science & 4.67 & 1.581 & 9 \\
& Commerce & 4.61 & .916 & 18 \\
& Total & 4.54 & 1.313 & 69 \\
& Arts & 4.31 & 1.681 & 230 \\
& Science & 4.88 & 1.516 & 97 \\
& Commerce & 4.60 & 1.924 & 90 \\
& Total & 4.50 & 1.713 & 417 \\
\hline
\end{tabular}

\section{ANOVA}

Table3.2- Stream -Arts, Science and Commerce

\begin{tabular}{|l|r|r|r|r|r|}
\hline Source & $\begin{array}{c}\text { Type III Sum } \\
\text { of Squares }\end{array}$ & df & Mean Square & \multicolumn{1}{c|}{ F } & \multicolumn{1}{c|}{ Sig. } \\
\hline Corrected Model & $103.587(\mathrm{a})$ & 11 & 9.417 & 3.415 & .000 \\
Intercept & 6085.914 & 1 & 6085.914 & 2207.298 & .000 \\
Schol_category & 65.020 & 3 & 21.673 & 7.861 & .000 \\
STREAM & 17.115 & 2 & 8.557 & 3.104 & .046
\end{tabular}


How Educator's Self-Efficacy affects Integration of Technology in the Classroom Teaching: ..

\begin{tabular}{|l|r|r|r|r|r|} 
Schol_category $*$ & 19.268 & 6 & 3.211 & 1.165 & .324 \\
STREAM & 1116.657 & 405 & 2.757 & & \\
Error & 9678.000 & 417 & & & \\
Cotal & 1220.245 & 416 & & & \\
\hline
\end{tabular}

\section{Analysis for $\mathrm{HO}_{3}$}

From the descriptive Table 3.1 we find that the average level of effective usefulness(negative) is 4.50 derived from all the respondents taken together collective from different streams and types of school. This indicates that all the respondents are in the opinion that usefulness of technology is limited to the subjects they teach in the classroom. The average level of usefulness of technology(negative) in Science in found to be lowest with the highest with average mean value of 4.88 (on 2 point rating scale). Followed by the educators belong to Commerce stream with the average mean value of 4.60 (on 2 point rating scale). The educators belonging to Arts stream have the lowest average mean with the mean value of 5.27 (on 2 point rating scale). The reading from the table 4.9 clearly depicted that educators belonging to Science streams are have the opinion that effective usefulness of technology is minimum in the classroom teaching in +2 school of Meghalaya. Educators belonging to science stream that usage of technology is not that essential to the teaching and learning process in the +2 schools of Meghalaya as the expertise cannot be derived by merely utilising the tools available in technology.

Conclusion from table 3.1 can also be drawn can be drawn for the responses from different types of school for usefulness of technology(negative). Table clearly shows that average mean for Govt. school has got the highest with the mean value of 4.95 (on 2 scale)rating. Followed by the Private school with the average mean value of 4.54(2 scale rating). The value of mean for Adhoc school is the second lowest with the mean value of 4.50( in 2 scale rating). And lastly, average mean of the Deficit school is the lowest with the mean value of 3.87 (on 2 scale rating). This clearly indicates that educators from Deficit schools have more positive opinion and find technology more useful in the classroom teaching in the +2 schools of Meghalaya even though they belong to different schools, teaching different subjects in different streams.

From the ANOVA Table 3.2 the F value for types of school is 7.864 and degree of freedom 3 with the corresponding $\mathrm{p}$ - value 0.000 which is smaller than the level of significance 0.05 .

Similarly from ANOVA table 4.10, the value of $\mathrm{F}$ for the stream is 3.104 and degree of freedom is 2 with the corresponding $\mathrm{p}$ - value of 0.046 which is smaller than the level of significant.

ANOVA table 3.2 clearly indicates that the value of F for Type of School * stream is 1.165 and degree of freedom is 6 with the corresponding p-value 0.324 which is greater than the level of significant. Hence we cannot reject the null hypothesis $\mathbf{H O}_{3}$.

\section{Findings:}

On the basis of analysis conducted for $\mathbf{H O}_{\mathbf{3}}$ after testing through Two Factor ANOVA, it is found that there is a usefulness of technology(negative) is not affect by the type of school they are employed and also the usefulness of technology is not affected by the stream. The result from ANOVA test also indicates that usefulness of technology is affected in the streams where educators are teaching in different types of school. It means that usefulness of the technology (negative) is not limited to the streams and different types of schools separately. Usefulness of the technology (negative) is based on the different streams where educators are teaching with regards to the types of schools they are working.

\section{CONCLUSION}

Self-efficacy with technology integration has a direct impact on how technology is used in teaching and learning, it is necessary to move beyond examining usage patterns and general attitudes toward technology in education and toward a better understanding of how self-efficacy beliefs emerge and what factors will have influence on these beliefs. While the educators of +2 schools examined in this study represent the only point in these educators preparation of lesson plan where the focus is directly on the integration of technology, it is beneficial to address the question of what impact can be expected from the educators' ability to integrate technology into the classroom. However, we presumed that these educators have limited experience in usage of technology in classroom teaching, researcher focused attention on self-efficacy beliefs in order to assess the potential of these educators to successfully integrate technology into their classroom teaching. The results of this pilot study suggest that some factors will have a more direct influence on self-efficacy beliefs than others. Based on this study, it is also possible to better focus future research on identifying specific practices that will have the highest impact on self-efficacy beliefs towards technology integration into teaching. 


\section{Changes in Attitudes and Self-Efficacy Beliefs}

Because a significant change in self-efficacy beliefs within groups was detected in all of the groups, the data suggests that all of the streams have a positive impact on the educator's beliefs about their own ability to integrate technology into teaching. These results further suggests that it is possible for self-efficacy beliefs to use the technology comfortably in their classroom teaching in +2 schools. However, these results also indicate that the impact these streams-Arts, Science and Commerce have on self-efficacy beliefs is not equal.

The changes in attitudes toward computer technology differed among the three groups. Significant changes in perceived comfort with computer technology occurred in all the three stream. This clearly indicates that comfort/anxiety for using technology in the classroom is totally depended on the subjects educators teach and to which stream they belong. No significant changes occurred in perceived usefulness of technology in any of the groups. Likewise no significant changes occurred in perceived non usefulness of technology in any of the groups. On observation of the study we can state self efficacy plays a very significant role in integration of technology in the classroom teaching but also streams where educator teach describes their willingness to use the technology in their classroom teaching. Result derived from the study will allow the researcher to conclude that the educators in Meghalaya are always willing to accept the news technology which will aid them in their teaching for the benefit of the student community.

"Teachers will not be replaced by technology, but teachers who don't use technology will be replaced by those who do."

\section{Limitations of this study}

One primary limitation of this study is the result of a focus on the three streams and the school types where educators are employed. While many aspects of these streams are common to many courses at other institutions, these three streams are not necessarily representative of all of the various models of exploring educators' perception to integrate technology. While these results are informative to those involved specifically in the three streams and types of schools included in the study, this focus also limits the ability to generalize these results to other course designs. Further, it is difficult to identify specific characteristics of these streams that may influence self-efficacy beliefs and attitudes toward technology due to the institutional barriers preventing random assignments of participants to a particular course.

An additional limitation to this study was the limited number of paired measurements that were available for data analysis. The number of participants was limited to the number of educators as prescribed in the selection of sample.

A third limitation to this study is the ability of the survey instruments and research design to identify the pattern of emergence of self-efficacy beliefs toward technology integration. Because of the length of the survey and the limited time available for the survey, it was not reasonable to administer the survey more than what has been design in the sample size, not covering all the educators in the state for more understanding their role of self efficacy in integrating technology in the classroom teaching. Also, the survey instrument is limited by its nature as a self-reporting instrument that relies on the ability of respondents to reliably respond to the survey items.

\section{REFERENCES}

[1]. Albion, P. R. (2001). Some Factors in the Development of Self-Efficacy Beliefs for Computer Use Among Teacher Education Students. Journal of Technology and Teacher Education, 9(3), 321-347.

[2]. Bandura, A. (1997). Self-efficacy: The Exercise of Control. New York: W.H. Freeman.

[3]. Becker, H. J. (1994) How Exemplary Computer-using Teachers Differ from Other Teachers: implications for realising the potential of computers in schools, Journal of Research on Computing in Education, 26, 291-321.

[4]. Compeau, D. R., \& Higgins, C. A. (1995). Computer self-efficacy: Development of a measure and initial test. MIS Quarterly, 19(2), 189.

[5]. Ely, D. P. (1999). New perspectives on the implementation of educational technology innovations. (Report No. IR-019-432). East Lansing, MI: National Center for Research on Teacher Learning. (ERIC Document Reproduction Service No. ED427775)

[6]. Enochs, L. G., Riggs, I. M., \& Ellis, J. D. (1993). The Development and Partial Validation of Microcomputer Utilization in Teaching Efficacy Beliefs Instrument in a Science Setting. School Science and Mathematics, 93(5).

[7]. Hadley, M. \& Sheingold, K. (1993) Commonalities and Distinctive Patterns in Teachers' Integration of Computers, American Journal of Education, 101, 261-315. 
[8]. Jaber, W. E., \& Moore, D. M. (1999). A survey of factors which influence teachers' use of computerbased technology. International Journal of Instructional Media, 26(3), 253-266.

[9]. Karsten, R., \& Roth, R. M. (1998). The Relationship of Computer Experience and Computer SelfEfficacy to Performance in. Journal of Research on Computing in Education, 31(1), 14.

[10]. Kellenberger, D. W. (1996). Preservice teachers' perceived computer self-efficacy. Journal of Research on Computing in Education, 29(2), 124.

[11]. Kinzie, M. B., Delcourt, M. A. B., \& Powers, S. M. (1994). Computer Technologies: Attitudes and SelfEfficacy Across Undergraduate Disciplines. Research in Higher Education, 35(6), 745-768.

[12]. Milbrath, Y.-c. L., \& Kinzie, M. B. (2000). Computer Technology Training for Prospective Teachers: Computer Attitudes and Perceived Self-Efficacy. Journal of Technology and Teacher Education, 8(4), 373-396.

[13]. Mourson, D., \& Bielefeldt, T. (1999). Will New Teachers be Prepared to Teach in a Digital Age? : Milken Exchange on Education Technology.

[14]. Torkzadeh, G., \& Koufteros, X. (1994). Factorial validity of a computer self-efficacy scale and the impact of computer training. Educational \& Psychological Measurement, 54(3), 813.

[15]. Torkzadeh, G., \& Van Dyke, T. P. (2002). Effects of training on Internet self-efficacy and computer user attitudes. Computers in Human Behavior, 18(5), 479.

[16]. Torkzadeh, G., Koufteros, X., \& Pflughoeft, K. (2003). Confirmatory Analysis of Computer SelfEfficacy. Structural Equation Modeling, 10(2), 263.

[17]. Wang, L., Ertmer, P. A., \& Newby, T. J. (2004a). Increasing Preservice Teachers' Self-Efficacy Beliefs for Technology Integration. Journal of Research on Technology in Education, 36(3), 231.

[18]. Wang, L., Ertmer, P. A., \& Newby, T. J. (2004b). Increasing Preservice Teachers' Self-Efficacy Beliefs for Technology Integration. Journal of Research on Technology in Education, 36(3), 231-250.

[19]. Zhang, Y., \& Espinoza, S. (1998). Relationships among computer self-efficacy, attitudes toward computers, and desirability of. Journal of Research on Computing in Education, 30(4), 420. 